\title{
Tackling obesity: new therapeutic agents for assisted weight loss
}

This article was published in the following Dove Press journal:

Diabetes, Metabolic Syndrome and Obesity:Targets and Therapy

23 April 2010

Number of times this article has been viewed

\author{
JG Karam \\ SI McFarlane ${ }^{2}$ \\ 'SUNY-Downstate-Kings County \\ Hospital, Brooklyn, NY, USA, \\ Maimonides Medical Center, Brooklyn, \\ NY, USA; '2Division of Endocrinology, \\ College of Medicine, State University \\ of New York-Downstate Medical \\ Center, New York, USA
}

Correspondence: Samy I McFarlane Professor of Medicine, Division of Endocrinology, Medical Director of Clinical Research College of Medicine, State University of New York-Downstate Medical Center, 450 Clarkson Avenue, Box 50, Brooklyn, New York, I I 203, USA $\mathrm{Tel}+\mid$ 7| $18-270-37||$

$\mathrm{Fax}+|7| 8-270-6358$

\begin{abstract}
The pandemic of overweight and obesity continues to rise in an alarming rate in western countries and around the globe representing a major public health challenge in desperate need for new strategies tackling obesity. In the United States nearly two thirds of the population is overweight or obese. Worldwide the number of persons who are overweight or obese exceeded 1.6 billion. These rising figures have been clearly associated with increased morbidity and mortality. For example, in the Framingham study, the risk of death increases with each additional pound of weight gain even in the relatively younger population between 30 and 42 years of age. Overweight and obesity are also associated with increased co-morbid conditions such as diabetes, hypertension and cardiovascular disease as well as certain types of cancer. In this review we discuss the epidemic of obesity, highlighting the pathophysiologic mechanisms of weight gain. We also provide an overview of the assessment of overweight and obese individuals discussing possible secondary causes of obesity. In a detailed section we discuss the currently approved therapeutic interventions for obesity highlighting their mechanisms of action and evidence of their efficacy and safety as provided in clinical trials. Finally, we discuss novel therapeutic interventions that are in various stages of development with a special section on the weight loss effects of anti-diabetic medications. These agents are particularly attractive options for our growing population of obese diabetic individuals.
\end{abstract}

Keywords: obesity, assisted weight loss, therapy

The recent decades have witnessed a rapidly growing pandemic of overweight and obesity with an estimated of more than 1.6 billion of overweight or obese adults worldwide and at least 400 million among them being obese. ${ }^{1}$ The number of obese individuals is expected to continue to escalate in the coming years in both developed and developing countries. In the western world, and specifically in the United States, the prevalence of obesity has increased by $50 \%$ in each of the past two decades with two thirds of US population currently being overweight, nearly half of whom are obese. ${ }^{2}$ According to the National Health and Nutrition Examination Survey (NHANES) of 2003-2004, a nationally representative sample of the US population, $17.1 \%$ of US children and adolescents were overweight and $32.2 \%$ of adults were obese, with the major increase of prevalence occurring alarmingly among children, adolescents and men during the 6-year period from 1999 to 2004 . $^{3}$ The NHANES data show that $71 \%$ of men and $62 \%$ of women are overweight or obese, with prevalence varying among the major racial/ethnic groups in the US. Furthermore, the prevalence of clinically severe obesity is increasing much faster than obesity itself. For instance, between 1986 and 2000, the prevalence of a body mass index (BMI) of 40 or greater quadrupled from about 
1 in 200 adult Americans to 1 in 50, and the prevalence of a BMI of 50 or greater increased by a factor of 5 , from about 1 in 2000 to 1 in $400 .^{4}$

Obesity has been historically associated with increased mortality and morbidity. The relationship between an increasing body weight and health risks is curvilinear with the BMI of 22 being associated with the lower risk. This link is clearly illustrated in the Framingham Heart Study that demonstrated increased risk of death by $1 \%$ for every pound of weight increase between the ages of 30 and 42 years and $2 \%$ between the ages of 50 and 60 years..$^{5}$ A more recent prospective study of a large National Institute of Health cohort suggested that the risk of death increased by $20 \%$ to $40 \%$ among nonsmoker overweight persons and by at least 2 to 3 times among obese persons. ${ }^{6}$

In addition to increased mortality, overweight and obesity have been associated with a wide spectrum of comorbidities including diabetes, hyperlipidemia, hypertension, cardiovascular disease, arthritis, gout, gastro-esophageal reflux, cholelithiasis, obstructive sleep apnea, nonalcoholic steatohepatitis and certain types of malignancies such as cancer of breast, endometrium, ovaries, gallbladder, prostate and colorectum. In addition, obesity is at the core of the metabolic syndrome and insulin resistance predisposing patients to increased risk of cardiovascular disease and type 2 diabetes.

The burden imposed by the obesity pandemic is multifaceted making obesity a public health priority. In addition to the multiple health adverse effects, economic impact of obesity has been significantly striking. ${ }^{7}$ For example, it is estimated that the total direct cost of obesity-associated morbidity in the US was US\$45.8 billion in 1990, representing $6.8 \%$ of all health care budget. ${ }^{8}$

Treating obesity should start by understanding the pathophysiologic processes leading to weight gain. Obesity is a complex disease that involves multiple interactions between genetic and environmental factors. It has been estimated that $30 \%$ to $40 \%$ of variance in BMI is due to genetic factors and $60 \%$ to $70 \%$ is thought to be environmental. ${ }^{9}$ Furthermore, the genotype of obesity might have different phenotypic expression depending on environmental factors such as high fat diet and sedentary lifestyles. The epidemic of obesity is believed to be, at least partially, related to environmental changes, including increase in caloric intake and decrease in physical activity, with subsequent modulation of obesity gene expression.

During the initial evaluation of an obese patient, the physician should perform a comprehensive assessment in order to identify possible secondary causes of obesity as well as associated comorbidities that should be targeted in therapeutic plan. Goal setting, lifestyle changes and therapeutic options will be discussed in this paper with an emphasis on the role of pharmacotherapy in treating obesity.

\section{Assessment of the obese patient}

Assessment of an obese patient includes both clinical and laboratory evaluation to determine the degree of obesity, potential secondary causes and associated comorbidites in order to provide bases for selection of appropriate therapy.

\section{Definition and severity of obesity}

According to the World Health Organization and the US National Institute of Health, obesity is defined as a BMI over $30 \mathrm{~kg} / \mathrm{m}^{2}$ and overweight as a BMI $>25 \mathrm{~kg} / \mathrm{m}^{2}$, with BMI being a standard clinical tool calculated by dividing a person's weight in kilograms by height in meters squared. ${ }^{10}$ Morbid obesity is defined by a BMI greater than 40 or a BMI greater than 35 with associated comorbidities (diabetes, hypertension, atherosclerosis). In pediatrics, overweight and obesity are defined by BMI $>85$ th and 95 th percentile respectively for age and sex for those aged 2 to 19 years.

BMI is an acceptable approximation of total body fat for most patients. However, those who are very muscular or have low muscle mass should have their total body fat determined from a monogram.

While BMI is the standard method of evaluating the overall degree of excess weight, measurement of waist circumference has emerged as a useful clinical tool in risk stratification of obese patients where increased central adiposity accounts for most of the increase of morbidity and mortality in this population. ${ }^{11}$ Excessive abdominal fat is associated with increased risk of diabetes mellitus, dyslipidemia, hypertension, cardiovascular disease, gallbladder disease, nonalcoholic fatty liver, sleep apnea, gout, osteoarthritis, and certain types of cancers, in addition to an overall increase in mortality A waist circumference greater than 40 inches $(102 \mathrm{~cm})$ in men and 35 inched $(88 \mathrm{~cm})$ in women is linked to higher cardiovascular risks and should lead to more aggressive weight reduction strategies in overweight patients.

\section{Assessment of associated comorbidities}

A major component of obesity management is the identification and treatment of associated comorbidities, specifically cardiovascular risk factors. In all overweight or obese patients, a careful medical history including age of onset 
of obesity, smoking, family history, alcohol consumption, dietary habits, level of exercise and medications should be obtained. Blood pressure should be measured and laboratory testing should be obtained for screening of diabetes and hyperlipidemia.

\section{Assessment of possible secondary obesity}

In addition to baseline evaluation, initial assessment should be oriented to rule out rare but potentially treatable secondary causes of obesity. ${ }^{12}$

Most cases of obesity are usually attributed to overeating with or without lack of exercise, translating into an increased energy intake and decreased energy expenditure leading to excess weight. Nevertheless, obesity could be less commonly related to underlying endocrinologic or genetic disorder. The patient should be screened clinically and if needed by laboratory testing for hypothyroidism, Cushing disease, hypogonadism, polycystic ovaries syndrome, Growth Hormone deficiency, hypothalamic disease and insulinoma. Such underlying diseases would require the initiation of appropriate and specific therapy.

On the other hand, the presence of hyperphagia and early severe obesity in a context of family history of early onset of obesity support a genetic disease such as leptin deficiency, whereas the presence of dysmorphic features with massive obesity in very young patients should suggest syndromic obesity such as Prader Willi Syndrome.

Certain medications can cause weight gain, including insulin, sulfonylureas, anti-epileptic drugs (carbamazepime, valproate), antipsychotic medications (clozapine, olanzapine) and some antidepressants (amitryptilin, paroxetine). Alternative medications should be always considered in this case.

Finally smoking cessation is traditionally linked to weight gain that could be prevented with nicotine replacement and bupropion.

\section{Therapeutic strategies for obesity}

The main principle in obesity management is achieving a negative caloric balance with reduced caloric intake and increased caloric expenditure that will inevitably lead to weight loss and particularly fat mass reduction. While this approach seems to be simplistic, the clinical experience indicates that only a minority of the population is able to apply and maintain negative caloric balance through decreased food intake and increased physical activity to the recommended 150 minutes per week.

\section{Overview of the current guidelines}

The alarming increase in overweight and obesity prevalence among the western population led to the development of several guidelines by national and international organizations, such as the National Heart, Lung, and Blood Institute (NHLBI), the American College of Physicians (ACP), and the United States Preventive Services Task Force (USPSTF). ${ }^{13-15}$ These guidelines are periodically updated to reflect the recent developments in the field of obesity management. Perhaps the most common theme among these guidelines is their ability to address the differential effect of obesity ie, total body fat versus abdominal obesity, as well as determining the absolute cardiovascular disease risk among the overweight and obese population. Based on this risk stratification, guidelines serve as tools for goal-setting behavioral and dietary therapy, lifestyle modification, as well as pharmacotherapeutic modalities. They also address other interventions as liposuction, bariatric surgery, highlighting risk/benefit ratio of these therapeutic options as a reflection of evolving data from clinical research in this area.

\section{Setting goals for the obese patient}

Setting goals for the obese patient prior to initiation of therapy is of crucial importance and helps identifying targets and motivations and avoiding frustrations and discontinuation of therapy. The main goal of treating an obese patient is to decrease his or her health risks of obesity-related metabolic disorders and cardiovascular disease, followed by psychological and secondary cosmetic benefits of weight reduction.

It has been clearly demonstrated that a modest weight reduction is sufficient to induce significant reduction of most comorbidities' risks, as illustrated in the Diabetes Prevention Program study where only $7 \%$ of body weight loss was associated with $58 \%$ reduction of progression to diabetes in individuals with impaired glucose tolerance. ${ }^{16}$ A modest weight loss (10\% of body weight) achieved through lifestyle changes is associated with significant improvement of glycemic control, blood pressure control and cholesterol level in obese patients with diabetes, hypertension and hyperlipidemia. ${ }^{17,18}$ Prolonged caloric restriction appears to improve longevity in rodents through beneficial metabolic effects and potential anti-aging effect. ${ }^{19}$

Therefore target weight loss of $5 \%$ to $10 \%$ of body weight at 6 months, translated into approximatively one pound weight loss per week $(0.45 \mathrm{~kg})$, is the recommended initial target and represents a realistic goal for these patients. Long-term goal is maintenance of reduced weight and further weight reduction if desired. ${ }^{11}$ 


\section{Therapeutic plan for the obese patient}

Behavioral changes represent the mainstay of treatment of obesity and are based on the combination of hypocaloric diet and increased physical activity. Patients with $\mathrm{BMI}>30$ or patients with $\mathrm{BMI}>27$ with one or more associated comorbidity who fail to achieve $5 \%$ of body weight loss after 6 months of therapeutic lifestyle changes should be offered pharmacotherapy as part of comprehensive program for weight loss. Bariatric surgery is reserved for patients with resistant severe obesity including patients with BMI $>40$ or patients with BMI $>35$ with associated comorbidities. Adjunctive therapy with herbal medications is not recommended as it contains unpredictable amount of active ingredients that can be harmful and lack safety data for short or long-term use. ${ }^{10}$

\section{Lifestyle changes in the management of obesity}

The management of obesity is based on either decreasing energy intake or increasing energy expenditure to target a negative energy balance translating in net weight loss. As food is the single source of energy intake, reducing nutrient intake is the cornerstone in treating obesity. On the other hand, Energy Expenditure is divided into Basal Metabolic Rate (BMR), Energy Expended in Activity (EAA), and thermic effect of food. EAA is the most variable component as it can account from $10 \%$ to $20 \%$ of total energy expenditure (in bedridden subjects) to $60 \%$ to $80 \%$ in athletes. Increasing energy expended in activity can increase total energy expenditure 4- to 8-fold and thus enhances weight loss significantly. Life therapeutic changes including hypocaloric diet and increased exercise are universally recommended as first line therapy in obese patients.

\section{Dietary interventions}

The core of dietary modifications in weight loss is to reduce caloric intake. The rate of weight loss is proportional to the negative energy balance between intake and expenditure. It is estimated that a decrease of $500 \mathrm{Kcal}$ energy intake per day leads to one pound weight loss in one week $(0.45 \mathrm{~kg})$. Energy expenditure however varies with individuals and can be influenced by gender, age and genetics, male gender and younger age being associated with higher energy expenditure.

\section{Hypocaloric diet}

Low calories diet (LCD) is universally recommended for weight loss. It can achieve $8 \%$ of body weight loss and reduce abdominal fat content in 6 months, along with improvement in associated metabolic parameters. ${ }^{10}$

Eucaloric diets provide approximatively 22 to $25 \mathrm{Kcal} / \mathrm{kg}$ of body weight, equivalent to 2200 to $2500 \mathrm{Kcal}$ in a person weighing $100 \mathrm{~kg}$. As outlined earlier, in order to achieve a $1 \mathrm{lb}$ weight loss weekly, an intake deficit of $500 \mathrm{Kcal} /$ day should be ensured. A low calorie diet usually provides 1000 to $1500 \mathrm{Kcal} /$ day, depending on the body weight and the weight loss rate desired. More severe caloric restriction could lead to more rapid weight loss at short term, but comparison of 400 versus $800 \mathrm{Kcal} /$ day showed no difference in weight loss in the long term. Moreover very low caloric diets $(<800 \mathrm{Kcal})$ are associated with substantial nutritional deficiencies, lean mass loss, greater weight regain secondary to stable decrease in energy expenditure and increased risk of gallstones and cholecystitis due to increased peripheral mobilization of cholesterol. ${ }^{18}$

Alcohol, junk food, sweets and beverages are commonly avoided in LCD in view of their high energy stores and lack of other nutritional benefits. A balanced diet is recommended to prevent excessive protein breakdown during energy restriction. Portions-controlled diet, where reduced caloric and nutritionally complete ready-to-use portions are provided in form of frozen meals and snack, has proven safety and efficacy in clinical trials. ${ }^{20}$

\section{Low fat diet}

Most obesity guidelines recommend decrease fat intake to less than $30 \%$ of total daily caloric intake, as high intake of saturated fats and trans fatty acids might be associated with obesity and increased cardiovascular risk. ${ }^{10}$ Although lower fat diets without caloric restriction help promote weight loss by reducing calorie intake, lower fat diets coupled with total calorie reduction produce greater weight loss than lower fat diets alone and are associated with beneficial cardiovascular effects. ${ }^{10}$

For example, the low calorie step I diet recommended by the National Cholesterol Educational Program (NCEP) advocates for a diet where Energy from total fat represent $30 \%$ or less of caloric intake, with $8 \%$ to $10 \%$ of saturated fat, up to $15 \%$ of monounsaturated fat, and up to $10 \%$ of polyunsaturated fat and less than $300 \mathrm{mg}$ of cholesterol per day. More than $55 \%$ of caloric intake is then provided by carbohydrates and no more than $15 \%$ by proteins. Advocates of low carbohydrate diet have blamed the increased intake of carbohydrates associated with low-fat diets in the escalation of obesity and developed therefore concept of low carbohydrate diet to achieve weight loss. ${ }^{21}$ 


\section{Low carbohydrate diet}

Low-carbohydrate diet has recently become very popular for weight loss. It consists of decreased amount of carbohydrate intake with no necessary restriction of energy intake. Atkins diet is a severely carbohydrate-restricted diet $(<20 \mathrm{~g} /$ day in the induction phase) that was described by Dr Atkins. The hypothesis behind this diet is that reducing insulin levels by reducing carbohydrate intake would lead to less hunger and fat deposit. Although it initially raised concern regarding a possible adverse effect on lipid metabolism and ketosis, several clinical trials have established the safety and efficacy of low carbohydrate diet in weight reduction, along with favorable effects on lipids, glucose and blood pressure. ${ }^{21}$

\section{Comparison of diets}

Several trials have compared the efficacy and the metabolic effects of different popular diets. ${ }^{22,23}$ The consensus is that the best diet remains the one that the patient will best and longest adhere to. Therefore the diet choice should be individualized and the different options and goals should be discussed with each patient.

\section{Increased physical activity}

Increased energy expenditure is a crucial component of any weight management program. In clinical trials, increased physical activity alone induced a slight weight loss $(0.1 \mathrm{~kg} /$ week $)$. Although exercise did not demonstrate any additive benefit in weight reduction when added to hypocaloric diet in some trials, ${ }^{24,25}$ moderate regular activity has consistently proven efficacy in weight loss maintenance and prevention of weight regain. ${ }^{26,27}$ Furthermore, it is believed that physical activity can help preventing loss of lean body mass in a hypocaloric diet, and may decrease abdominal fat even without associated weight loss. ${ }^{28}$ Beyond weight reduction effect, physical fitness improves insulin sensitivity along with glycemic, lipid and blood pressure control and is believed to reduce cardiovascular risk. ${ }^{10}$

Overweight or obese patient should be advised 30 to 45 minutes of moderate intensity activity for 5 days weekly in adjunction to diet therapy. ${ }^{29}$ With this regimen, an additional 100 to 200 calories per day of energy can be expended. Calorie expenditure will vary depending on the individual's body weight and intensity of activity. ${ }^{10}$ Individuals at risk should undergo exercise-stress testing before initiation of activity program. In order to reduce barriers of cost and to optimize adherence, home-based exercise program including walking and using stairs, along with dividing activity in intermittent daily sessions, are effective strategies in implementing physical activity in the weight management program. ${ }^{30}$

\section{Other nonpharmacologic therapy of obesity}

Several trials have examined the effect of acupuncture on weight loss in obese subjects. Two recently published metaanalyses have shown significant although moderate weight reduction $(0.5-3 \mathrm{~kg})$ with acumpuncture when compared with placebo, lifestyle changes or sibutramine..$^{31,32}$ Interestingly, in a recent randomized controlled trial comparing auricular acupuncture with sham auricular acupuncture using placebo needles in 45 overweight or obese patients, no significant difference of weight reduction was achieved but changes in ghrelin and leptin levels were more favorable in the intervention group. ${ }^{33}$

The limited duration, quantity and poor methodoligic quality of these trials weaken the evidence of efficacy of acupuncture in obesity and underline the need for larger randomized controlled studies to evaluate this safe and possibly effective weight reducing intervention.

\section{Pharmacologic treatment of obesity}

The National Heart, Lung and Blood Institute of the National Institutes of Health recommend to add pharmacologic therapy to treat overweight or obesity in patients with BMI $>30$ or patients with BMI $>27$ with obesity associated comorbidity who had failed to lose weight after 6 months of lifestyle interventions. ${ }^{14}$

Despite the limited compliance and long-term efficacy of lifestyle changes along with the dramatic increase of prevalence of obesity and its associated health cost and comorbidities, very few medications have been developed to match the need for therapeutic agents targeting obesity. Only two medications (orlistat and sibutramine) are recently approved to be used, in conjunction with diet and exercise, for long-term therapy of overweight or obese patients. Older medications approved for short-term use of obesity more than 30 years ago lack data on efficacy and safety beyond 6 months of treatment.

Based on their mechanism of action, weight-reducing agents can be mainly divided in two categories: medications that decrease energy intake through early satiety or appetite suppression (through increase of anorexigenic neurotransmitters such as epinephrine, serotonin and dopamine) and absorption inhibitors (orlistat). 


\section{Medications approved for long-term treatment of obesity \\ Orlistat}

Mechanism of action

Orlistat is the only absorption inhibitor available for treatment of obesity. In the USA, it was approved by the Food and Drug Administration (FDA) in 1999 for treatment of obesity and maintenance of weight loss, in conjunction with hypocaloric diet and exercise.

Orlistat is a nonsystemic hydrogenated derivative that reversibly binds to gastrointestinal lipase, interfering with the absorption of dietary fat by inhibiting the hydrolysis of fat into absorbable fatty acids and glycerol, leading to excessive fecal fat excretion. It is estimated that the absorption of up to $30 \%$ of dietary fat can be blocked by orlistat in a dose-dependent effect, therefore reducing total fat and caloric intake. ${ }^{34}$ In healthy subjects, the effect of orlistat on gastric lipase was very fast and potent (46.6\%-91.4\% of gastric lipase inhibition within minutes) whereas duodenal lipolysis reduction was more pronounced with the solid meal than liquid meals. ${ }^{35}$ Human pancreatic lipase inhibition was found to be high regardless of the meal. Overall, the effects of orlistat on fat excretion levels were found to be much greater with the solid ( $40.5 \%-57.4 \%$ of ingested fat) than with the liquid $(4.2 \%-18.8 \%)$ test meals. ${ }^{35}$

The increased amount of fat reaching the colon can lead clinically to intestinal cramps, flatulence, diarrhea, fecal incontinence and oily spotting. ${ }^{36}$ Decreased oral fat intake minimizes the intestinal side-effects, promoting a better adherence to low-fat diet and providing an additional potential mechanism of weight loss in these patients. It has been thought that such low-fat diet can be associated with increased carbohydrates intake, potentially accounting for the slow weight regain observed on the second year of the treatment with orlistat. ${ }^{37}$ However an overall favorable glycemic effect has been observed in patients with impaired glucose tolerance treated with orlistat. $^{38}$

\section{Pharmacokinetics}

Orlistat is minimally absorbed from the gastrointestinal tract. Systemically absorbed orlistat appears to be degrraded into two major metabolites. The major route of elimination is via the feces (primarily unabsorbed drug); less than $5 \%$ of a dose appears in the urine. A small degree of biliary excretion may occur. The local half-life of orlistat is 1 to 2 hours.

\section{Efficacy in clinical trials}

More than 29 randomized controlled studies evaluated the effect of orlistat on weight reduction and other metabolic parameters in different populations. ${ }^{39}$

At least 4 randomized, double-blinded placebo controlled trials of orlistat lasting two years have been published. Orlistat therapy was consistently associated with a modest weight loss, peaking at around 8 months of treatment, followed by a progressive weight regain during the second year of treatment. ${ }^{38,40,41}$ For example, in one European multicenter study, 688 obese participants were assigned double-blind treatment with orlistat $120 \mathrm{mg}$ ( 3 times a day) or placebo in conjunction with hypocaloric diet for the first year, and were reassigned double-blind treatment with orlistat or placebo with a weight maintenance (eucaloric) diet for the second year. ${ }^{40}$ In the first year, the group treated with orlistat lost significantly more weight than the placebo group (10.2\% of initial body weight versus $6.1 \%, P<0.001)$. During the second year, patients who continued with orlistat had almost half of the weight regain observed in those switched to placebo $(P<0.001)$, whereas patients switched from placebo to orlistat lost additional $0.9 \mathrm{~kg}$ during the second year of trial, compared with a mean weigh regain of $2.5 \mathrm{~kg}$ in patients who continued on placebo $(P<0.001){ }^{40}$

The XENical in the prevention of diabetes in obese subjects (XENDOS) study provided data on 4 years orlistat treatment, which represents the longest duration of an obesity medication trial. ${ }^{38}$ In a double-blind, prospective study, 3305 obese patients were randomized to lifestyle changes plus either orlistat $120 \mathrm{mg} 3$ times a day or placebo. The maximal body weight decrease was achieved during the first year ( $>11 \%$ of initial body weight) in the orlistat-treated group compared to $6 \%$ decrease in the placebo-treated group. Despite gradual regain during the remaining 3 years, mean weight loss after 4 years was significantly greater with orlistat when compared to placebo (5.8 vs $3.0 \mathrm{~kg}$ with placebo; $P<0.001)$.

As shown by the above-mentioned studies, orlistat has also proven efficacy in weight loss maintenance. A multicenter double-blind, placebo-controlled study demonstrated the superiority of orlistat at the dose of $120 \mathrm{mg} 3$ times a day, when compared to placebo, in preventing weight regain in 729 subjects who succeeded to lose $>8 \%$ of their initial body weight during a 6-months lead-in of a hypocaloric diet. ${ }^{42}$ At 1 year, the placebo-treated patients regain $56 \%$ of their body weight, compared with $32.4 \%$ in the group treated with orlistat $120 \mathrm{mg} 3$ times a day. ${ }^{42}$ 
In summary, orlistat is associated with $5 \%-10 \%$ body weight reduction and slower weight regain. ${ }^{43}$ In a metanalysis, Li reported an average of additional $2.89 \mathrm{~kg}$ of weight reduction (compared to placebo and diet), and a total of $8.13 \mathrm{~kg}$ weight loss at one year with orlistat therapy. ${ }^{39}$

\section{Metabolic effects}

In addition to its weight reducing properties, multiple studies demonstrated beneficial effects of orlistat on glucose and lipid metabolism. $38,40,42,44-47$

Orlistat therapy consistently demonstrates a favorable lipid effect beyond the effect of weight loss in overweight or obese patients with concomitant hypercholesterolemia. ${ }^{35}$ The majority of clinical trials reported significant decrease of total cholesterol and LDL-cholesterol levels when compared to diet therapy alone. In a metanalysis, Hutton described a mean 6 months reduction of $0.43 \mathrm{mmol} / \mathrm{L}$, $0.34 \mathrm{mmol} / \mathrm{L}, 0.06 \mathrm{mmo} / \mathrm{L}$ and $0.08 \mathrm{mmol} / \mathrm{L}$ in total cholesterol, low-density lipoprotein (LDL) cholesterol, highdensity lipoprotein (HDL) cholesterol and triglycerides respectively, fact that was observed in both low and high cardiovascular risk patients as well as diabetic patients. ${ }^{43}$

Moreover, orlistat therapy is associated with a favorable glycemic effect.

In the XENDOS study, orlistat treatment reduced the 4 year cumulative incidence of diabetes by $37.3 \%$ when compared to placebo $(9.0 \%$ vs $6.2 \%, P=0.0032) .{ }^{38}$ Further subanalysis revealed that this diabetes prevention effect was mostly explained by a significant reduction of progression to diabetes in participants with impaired glucose tolerance test, who represented $21 \%$ of the study population.

Several clinical trials assessed the efficacy of orlistat strictly in diabetic patients. ${ }^{48,49}$ In Hutton's metanalysis, one year of orlistat therapy was found to be significantly associated with a mean decrease of $0.4 \%$ of glycated hemoglobin $\mathrm{A}_{1 \mathrm{C}}\left(\mathrm{HbA}_{1 \mathrm{C}}\right)$ and a mean decrease of $0.83 \mathrm{mmnol} / \mathrm{L}$ of fasting blood sugar, along with greater orlistat-induced reduction of dosage of antidiabetic medications such as insulin, metformin and/or sulfonylureas. ${ }^{43}$

\section{Clinical trials in adolescents}

In 2003, The FDA approved the use of orlistat for treating obesity in adolescents, based on the results of a multicenter, 54-week, randomized, double-blind study of 539 obese adolescents conducted in the US and Canada, where treatment with orlistat at a dose of $120 \mathrm{mg} 3$ times daily was safe and achieved greater weight reduction when compared to placebo. ${ }^{41}$ At the end of the study, BMI decreased by 0.55 with orlistat but increased by 0.31 with placebo $(P=0.001) .{ }^{41}$

\section{Safety and tolerability}

Orlistat has generally been considered a safe medication as it is mostly not absorbed. However it can interfere with the absorption of fat-soluble vitamins such as vitamins D, A, K, E and beta-carotene. Levels of these vitamins, especially vitamin $\mathrm{D}$ levels, were observed to be lowered during therapy. ${ }^{36}$ There was no report of increased risk of gallstones or kidney stones with orlistat. ${ }^{36}$

Except for cyclosporine which should be given two hours before or after orlistat, there is no major drug interactions described with orlistat. ${ }^{36}$

As mentioned earlier, orlistat has side effects related to fecal fat loss that include soft or liquid stools, oily stools, fecal incontinence, abdominal pain, oily spotting, nausea and vomiting. These gastrointestinal side effects affected $15 \%$ to $30 \%$ of patients across different clinical trials and usually subsided in $15 \%$ to $30 \%$ of patients after a few weeks of treatment. ${ }^{36} \mathrm{~A}$ randomized controlled study of sixty obese women receiving orlistat with psyllium mucilloid or orlistat with placebo suggested that the addition of natural fibers can ameliorate the gastrointestinal side-effects of orlistat without decreasing its efficacy. ${ }^{50}$

In August 2009, the FDA posted an early communication about an ongoing safety review regarding reports of liverrelated adverse events in patients taking orlistat..$^{51}$ Between 1999 and October 2008, 32 reports of serious liver injury, 27 of which required hospitalizations, including 6 cases of liver failure, were reported to the FDA's Adverse Events Reporting System. Thirty of the 32 reports occurred outside the US. The most common reported adverse effects were jaundice, weakness and abdominal pain. FDA analysis of the data is still ongoing and no definite association between liver injury and orlistat has been established at this time. ${ }^{51}$

Orlistat therapy is contraindicated in patients with malabsorption or cholestasis and should be used with caution in patients with history of calcium oxalate nephrolithiasis or at who are at high risk of fat-soluble vitamin D deficiency.

\section{Availability, dosage and administration}

Orlistat is approved for marketing in approximately 100 countries. In the US, it is two products aremarketed: Xenical $^{\circledR}$ (orlistat $120 \mathrm{mg}$ ) was approved as a prescription product by FDA in 1999 for obesity management in conjunction with a reduced caloric diet, and for weight 
reduction maintenance. In 2007, $\mathrm{Alli}^{\circledR}$ (orlistat $60 \mathrm{mg}$ ) was approved for OTC use for weight loss in overweight adults, 18 years and older, in conjunction with a reduced-calorie and low-fat diet. In January 2009, a nonprescription version of orlistat was approved for sale in the European Union.

Orlistat is usually administered at the dose of 60 or $120 \mathrm{mg}$ by mouth 3 times a day before or up to 1 hour after fat-containing meals. Treatment with orlistat should be associated with balanced and hypocaloric diet where approximately $30 \%$ of caloric intake is from fat. Although vitamin deficiency was not observed to be clinically relevant in the studies, it is recommended to supplement patients with oral multivitamins, to be taken apart from xenical, usually at bedtime.

\section{Sibutramine (Reducti ${ }^{\circledR}$, Meridia $^{\circledR}$ ) \\ Mechanism of action}

Sibutramine is the only sympathomimetic drug approved for long-term treatment of obesity in Europe and the US. It was approved by the FDA in 1997 for long-term therapy of obese patients with or without diabetes, hyperlipidemia and/or stable hypertension.

Sibutramine acts, at the nerve uptake, through the mixed selective inhibition of reuptake of norepinephrine and serotonin (5-hydroxytryptamine, 5-HT), and to a lesser degree dopamine, by centrally decreasing appetite. The drug and its metabolites bind weakly to serotonin (5-HT(1), 5-HT(1A), 5-HT(1B), 5-HT(2A) and 5-HT(2C)), dopamine (D(1) and $\mathrm{D}(2)$ ), norepinephrine (beta, beta(1), beta(3), alpha(1) and alpha(2)), benzodiazepine and glutamate (N-methylD-aspartate (NMDA)) receptors. It does not possess any anticholinergic or antihistaminergic activity and it does not stimulate the release of serotonin, norepinephrine or dopamine.

In clinical trials, short-term as well as long-term sibtramine treatment was associated with decreased appetite and respectively an average of $16 \%$ and $27 \%$ reduction in the amount of food intake. ${ }^{52}$

In addition to appetite suppression, a thermogenic effect was also observed in animal models but has been controversial in humans. ${ }^{53}$

\section{Pharmacokinetics}

Sibutramine is rapidly absorbed after oral administration and reaches its peak plasma concentration within 1 to 2 hours after administration. The drug and its active metabolites (monodesmethyl M1 and didesmethyl M2) are mostly bound to proteins and undergo hepatic metabolism by cytochrome P450 enzymatic system (isoenzyme CYP3A4), causing eventual interference with many drugs, specifically eryhtromycine and ketokonazole. The majority of excretion is renal with a half life of active metabolites of 14 to 16 hours.

\section{Clinical trials}

Several randomized controlled trials evaluating sibutramine and lasting for 6 to 24 months have been published. ${ }^{26,54-58}$

In a multicenter dose-ranging study, 1047 obese subjects were assigned to treatment with 1 of 6 doses of sibutramine $(1,5,10,15,20$, or $30 \mathrm{mg})$ or placebo once daily for 24 weeks. ${ }^{57} \mathrm{~A}$ significant dose-related weight reduction, ranging from $3.9 \%$ to $9.4 \%$ of body weight, was demonstrated across all time-points for a $5 \mathrm{mg} /$ day to $30 \mathrm{mg}$ /day dosage of sibutramine compared to placebo. Weight regain was observed after discontinuation of the medication.

Sibutramine efficacy in weight loss maintenance has been evaluated in three randomized controlled studies. ${ }^{26,56,58}$ In a European milticenter trial, The Sibutramine trial in Obesity Reduction and Maintenance, 605 obese patients were treated for 6 months with sibutramine $10 \mathrm{mg}$ daily and hypocaloric diet. ${ }^{58}$ The 467 subjects who achieved more than 5\% weight loss were then randomly assigned to $10 \mathrm{mg}$ /day sibutramine or placebo for a further 18-month period. Only $16 \%$ of the placebo group subjects maintained $80 \%$ or more of their original weight loss at 2 years, compared with $43 \%$ in the sibutramine group. Similar findings were observed with the other maintenance trials.

The possibility of intermittent treatment with sibutramine was examined in a German randomized, double-blind, parallel-group placebo-controlled trial. In this 48-week trial, 1001 obese subjects were randomly assigned to receive sibutramine $15 \mathrm{mg}$ daily continuously, sibutramine $15 \mathrm{mg}$ daily intermittently during weeks 1-12, 19-30, and 37-48, with placebo during the other weeks or just placebo after the run in period. Mean additional weight loss achieved at 44 weeks was $3.8 \mathrm{~kg}(4.0 \%)$ and $3.3 \mathrm{~kg}(3.5 \%)$ in patients receiving continuous and intermittent therapy respectively, versus a mean weight gain of $0.2 \mathrm{~kg}(0.2 \%)$ in patients receiving placebo, demonstrating a therapeutic equivalence and a similar safety profile of the two sibutramine regimens.

Of note, one behavioral study demonstrated that the combination of sibutramine and lifestyle changes was significantly at least twice more effective than either therapy alone, underlying the importance of conjunction of lifestyle counseling with pharmacotherapy. ${ }^{59}$

In summary, clinical trials demonstrated the efficacy of sibutramine, in conjunction with lifestyle changes, in weight 
loss induction and maintenance. Among several published meta-analysis, Li et al estimated the mean difference of weight loss with sibutramine to be $4.45 \mathrm{~kg}$ when compared to placebo in 5 long-term studies (44-54 weeks). ${ }^{39}$

\section{Metabolic and cardiovascular effects}

Favorable metabolic effects have been consistently observed with sibutramine across several clinical studies.

Several double-blinded controlled trials and meta-analysis have assessed the effect of sibutramine in diabetic patients. ${ }^{60-62}$ In addition to a mean difference of weight loss of $4.63 \mathrm{~kg}$ when compared to placebo, sibutramine was associated with decreased waist circumference along with slight decrease in $\mathrm{HbA}_{1 \mathrm{C}}$ and fasting blood glucose levels in obese patients with diabetes. ${ }^{61}$ These changes correlated with the magnitude of weight loss achieved.

Favorable lipid effects were also reported in diabetic and nondiabetes patients with specifically lower triglycerides and higher HDL cholesterol in sibutramine treated patients when compared to placebo-treated subjects. Nonetheless, this effect was not consistent in Li et al meta-analysis. ${ }^{39}$

Sibutramine use was commonly associated with a slight increase in diastolic and systolic blood pressure $(1-3 \mathrm{mmHg})$ and slight increase in heart rate ( 4 beats per minute). ${ }^{39,63}$ This increase is probably linked to norepinephrin effect of sibutramine. Beta-blockers do not appear to prevent this effect. ${ }^{64}$ In a subgroup analysis, the effect on systolic blood pressure was greater with higher doses ( $>15 \mathrm{mg}$ daily), in younger patients ( $<44$ years of age) and individuals weighing above $92 \mathrm{~kg} .{ }^{65}$ Few randomized controlled study of sibutramine use in hypertensive patients have been published and revealed slight increase in diastolic blood pressure and heart rate. ${ }^{64,66-68}$ Interestingly, in a recent study of hypertensive obese patients on different antihypertensive combined regimens, Scholze et al demonstrated that angiotensin-converting enzyme inhibitors and calcium channel blockers are more advantageous than a beta-blocker/diuretic-based regimen in supporting the weight-reducing actions and concomitant metabolic changes induced by sibutramine in obese hypertensive patients. ${ }^{68}$

\section{Clinical trials in adolescents}

Sibutramine was also evaluated in the treatment of obesity in adolescents. ${ }^{69,70}$ In a US multicenter randomized doubleblind trial, 498 obese adolescents received site-specific behavior therapy plus sibutramine daily or placebo. At 12 months, the sibutramine group had greater reduction in BMI $\left(-2.9 \mathrm{~kg} / \mathrm{m}^{2}\right)$ and body weight $(-8.4 \mathrm{~kg})$ than placebo group, with favorable lipid and glycemic effect.

\section{Safety and tolerability}

Unlike older appetite suppressants, fenfluramine and dexfenfluramine, sibutramine does not cause increased serotonin release and has not been associated with the development of valvular disease. ${ }^{71,72}$

However, in view of the associated increased sympathetic activity, sibutramine can cause slight elevation in heart rate and both diastolic and systolic blood pressure and should therefore be used cautiously in patients with uncontrolled hypertension, arrhythmia, coronary heart disease or congestive heart failure. It should be avoided as well in patients receiving other sympathomimetic drugs, monoamine oxidase inhibitors or serotonin uptake inhibitors.

Studies have shown that patients with well controlled hypertension on ACE inhibitors or beta blockers with or without thiazides appear to achieve significant weight loss with sibutramine with no compromise of blood pressure control. $^{64,67}$

The most common side-effects of Sibutramine are usually related to sympathomimetic properties, such as dry mouth, anorexia, constipation, headaches and insomnia.

\section{Availabiltiy, dosage and administration}

Sibutramine is marketed in the US under the brand name of Meridia ${ }^{\circledR}$ and in Europe under the name of Reductil ${ }^{\circledR}$. Although below the maximally efficacious dosage, sibutramine is approved at the dosage of 10 or $15 \mathrm{mg}$ daily as increased cardiovascular side-effects are reported with higher doses. The recommended starting dose is at $10 \mathrm{mg}$ daily and can be titrated after 4 weeks of therapy according to patient's response and tolerability. Blood pressure and high rate should be monitored during dose titration. Non-responders can be identified in the first few weeks of the treatment and unnecessary prolonged treatment can be avoided in these patients.

\section{Combination of sibutramine and orlistat}

As sibutramine and orlistat act through different mechanisms, the combination of the two medications was thought to give potential additive benefits in obesity. However several studies failed to show superiority of the combination on the use of sibutramine alone. In one study, 34 obese women who had lost an average of $11.6 \%$ of initial body weight during the prior year of treatment with sibutramine and lifestyle modification were randomly assigned to sibutramine plus orlistat or sibutramine plus placebo. At 16 weeks, mean body weight did not change significantly in either treatment arm suggesting no additive effect of the combination of orlistat with sibutramine. ${ }^{73}$ In another 12 -week, randomized, 
open-labeled trial, 86 obese subjects were randomly treated with sibutramine, orlistat, combination of the two drugs or diet alone. Sibutramine and the combination therapy were equally effective in reducing BMI, and were both significantly more effective than orlistat therapy alone. ${ }^{74}$ Similar findings were reported by other investigators as well. ${ }^{74-76}$

\section{Rimonabant (Acomplia ${ }^{\circledR}$ )}

Rimonabant is a selective cannaboid receptor 1 (CBR1) antagonist that was previously approved by the European Medicinal Evaluation Agency (EMEA), but not by the FDA, for long-term treatment of obesity in adjunction with diet and exercise.

CB1 are distributed in the brain and adipose tissue; when activated by endogenous ligands (anandamide and 2-arachidonyl glycerol), CB1 receptors stimulate fat and sweet food intake. In animals, administration of CBR1 agonists induce hyperphagia whereas CB1R antagonists prevent compensatory overeating during forced starvation in rats. High fat diet failed to induce obesity in mice lacking $\mathrm{CB} 1 \mathrm{R}$ because of a spontaneously reduced caloric intake. ${ }^{77}$ In addition to their role in appetite regulation, CB1R antagonists might increase energy expenditure in animal models.

Therefore CB1R blockade has emerged over the past decade as a new therapeutic option in obesity and cardiovascular risk management.

Three multicenter one-year trials and one two-years trial were included in the phase III assessment of Rimonabant for treatment of obesity: the Rimonabant in Obesity (RIO) - Europe study ( $\mathrm{N}=1507$ obese or overweight subjects), ${ }^{78}$ the RIO-Lipids study ( $\mathrm{N}=1036$ overweight or obese patients with dyslipidemia) ${ }^{79}$ the RIO-Diabetes study ( $\mathrm{N}=1047$ overweight or obese patients with uncontrolled type 2 diabetes) ${ }^{80}$ and the RIO-North America (3045 obese or overweight adult). ${ }^{81}$ Rimonabant was consistently associated with an average additional weight reduction of $4.9 \mathrm{~kg}$ (dose of $20 \mathrm{mg}$ ) and $1.3 \mathrm{~kg}$ (dose of $5 \mathrm{mg}$ ) compared to placebo. ${ }^{82}$ In addition, rimonabant exhibited consistently across these trails several favorable metabolic effects such as improvements in waist circumference, HDL-cholesterol, triglycerides, insulin resistance, and prevalence of the metabolic syndrome. ${ }^{78-83}$ The metabolic effects were mostly observed with the dosage of $20 \mathrm{mg}$. A potential effect on atherosclerosis was also studied. ${ }^{84}$

According to a systematic review by Curioni, rimonabant $20 \mathrm{mg}$ caused significantly more adverse effects both of general and serious nature, especially of nervous system, psychiatric or gastro-intestinal origin. ${ }^{82}$ Despite similar high drop-out rates in rimonabant and placebo groups (36\%-49\% at 1 year), side-effects including mood changes, nausea, vomiting, diarrhea, headaches and anxiety were more frequent in the rimonabant $20 \mathrm{mg}$ group.

Rimonabant use was associated with increased neurologic and psychiatric adverse effects including seizures, depression, anxiety, aggressiveness and suicidal thoughts despite depressive mood being an exclusion criteria for the clinical trials. ${ }^{85}$ In 2007, increased suicidal risk raised special concern in the FDA panel who advised against the approval of the medication in the US. More recently, the European Regulatory authorities have removed marketing approval for rimonabant because of postmarketing associated serious psychiatric side-effects including reported deaths of suicide. The manufacturers of the drug subsequently terminated clinical trials with rimonabant.

\section{Medications approved for short-term treatment of obesity}

Sympathomimetics

Mechanism of action

Decades prior to sibutramine, noradrenergic drugs have been approved for short-term therapy of obesity and include: phentermine (FDA approved in 1959), diethylpropion, benzphetamine and phendimetrazine. These medications stimulate the release of norepinephrine or inhibit its reuptake into nerve terminals and act centrally as appetite suppressants.

Phenylpropanolamine has been withdrawn from the market because of increased risk of hemorrhagic stroke in women. ${ }^{86}$

Other serotonergic agents (fenfluramine and dexfenfluramine) were also withdrawn from the US market in 1997 because of association with valvular heart disease and pulmonary hypertension that are believed to be related to the nonselective effect of increased serotonin levels on cardiac 5 HT receptors. ${ }^{87,88}$

\section{Clinical trials}

Most of the data on sympathomimetics come from short-term trials. In a meta-analysis, of nine randomized controlled studies of phentermine and thirteen clinical trials of diethylpropion, phentermine 15 to $30 \mathrm{mg}$ daily and diethylpropion $75 \mathrm{mg}$ daily were associated with additional $3.6 \mathrm{~kg}$ and $3.0 \mathrm{~kg}$ of weight loss respectively when compared to placebo. ${ }^{89} \mathrm{In}$ two 36-week trials, weight loss achieved with phentermine was up to $13 \%$ of initial body weight, reflecting its high efficacy. ${ }^{90}$ 


\section{Safety and tolerability}

Phentermine and diethylpropion are classified by the US

Drug Enforcement Agency as class IV medications while benzphetamine and phendimetrazine are classified as class III, suggesting a potential, although low risk of abuse with these medications. Although no major side effects were reported, these medications could potentially be associated with adverse effects related to increased sympathetic drive such as insomnia, euphoria, palpitations, dry mouth, and increased blood pressure.

Their use is approved for short term, usually up to 12 weeks and represents the least expensive available obesity drugs in the market.

\section{Medications associated with weight loss but not approved for obesity treatment}

\section{Antidepressants}

Selective serotonin reuptake inhibitors (SSRIs)

Fluoxetine and sertraline are two SSRIs approved for treatment of depression. Their use has been linked with weight loss that is thought to be secondary to appetite suppression and decreased food intake.

In a meta-analysis of nine studies of fluoxetine used at a dose of $60 \mathrm{mg}$ daily (3 times usual dose for depression) as a treatment for obesity, the weight reduction with fluoxetine ranged from $-0.9 \mathrm{~kg}$ to $-9.1 \mathrm{~kg}$ at 6 months and from $-14.4 \mathrm{~kg}$ to $+0.3 \mathrm{~kg}$ at 12 months compared to placebo. In summary at one year the weight regain ablated the previous weight loss observed at 6 months, suggesting a limited efficacy of fluoxetine to short term therapy. ${ }^{39,91,92}$

In a study assessing the effect of sertraline in weight maintenance in 53 women who lost weight with lifestyle changes, there was no significant difference in weight regain between sertraline group and placebo group. ${ }^{93}$

Despite lack of extensive data and demonstrable longterm efficacy, fluoxetine and sertraline represent a viable option in treating obese patients with depression.

\section{Bupropion}

Bupropion is approved for treatment of depression and for adjunctive therapy for prevention of weight gain in smoking cessation. It is a weak serotonin, norepinephrine and dopamine reuptake inhibitor with structural similarity to diethylpropion.

Pooled analysis of weight loss from three randomized controlled studies showed that bupropion at $400 \mathrm{mg}$ daily was associated with a total weight loss of $4.44 \mathrm{~kg}$ at 12 months and additional $2.77 \mathrm{~kg}$ when compared to placebo. ${ }^{39,94}$ Insomnia and dry mouth are commonly reported side-effects. Bupropion is contraindicated in patients with seizure disorders. The use of bupropion as a weight reducing agent is limited by the lack of large trials examining its efficacy in obese patients.

\section{Antiepileptics}

\section{Topiramate}

A novel antiepileptic agent, topiramate, is approved for treatment of seizures and migraine headaches but has been observed to be associated with decreased food intake and weight loss in multiple seizures studies. The mechanism of action on appetite suppression is not clearly understood but GABA pathway modulation is a potential mediator of weight loss. Several trials have been subsequently conducted to assess its efficacy in obesity treatment. In a meta-analysis of 6 randomized controlled trials evaluating topiramate as a weight reducing agent, topiramate at the dose of $192 \mathrm{mg}$ daily was associated with additional $6 \%$ of initial body weight loss at 6 months when compared to placebo. ${ }^{39}$ Moreover, topiramate seems to play a therapeutic role in binge-eating disorders. ${ }^{95,96}$ Paresthesias, somnolence, attention deficit, changes in taste, nonanion gap acidosis and with kidney stones are more commonly observed with topriamate treated patients. These side-effects have limited the development program for topiramate indication for overweight treatment.

\section{Zonisamide}

Zonisamide is an antiepileptic drug with serotonergic and dopaminergic properties, that has been linked to weight loss in epilepsy studies. To examine a potential role in obesity treatment, a double-blind, placebo-controlled trial was conducted for 16 weeks, assigning randomly 60 obese subjects to receive zonisamide (100 $\mathrm{mg}$ up to $600 \mathrm{mg}$ daily) or placebo, in addition to a hypocaloric diet for both groups. ${ }^{97} \mathrm{At}$ 16 weeks, zonisamide treatment was associated with greater body weight loss when compared to placebo ( $6 \%$ versus $1 \%)$. The participants who entered the single-blind treatment extension phase continued to lose weight at 32 weeks.

The most common side-effects associated with the use of zonisamide include somnolence, anorexia, dizziness, headache, nausea, and irritability.

\section{Antidiabetic medications \\ Metformin}

Metformin is a biguanide used in the treatment of diabetes and acts by inhibiting hepatic glucose production and improving insulin sensitivity. In diabetic patients, the use of metformin was associated with modest weight loss when compared to sulfunyloreas and insulin. ${ }^{11,75}$ 
In the multicenter Diabetes Prevention Trial enrolling 3234 overweight patients with impaired fasting glucose or impaired glucose tolerance test, metformin treatment for 2.8 years was associated with $2.5 \%$ of initial body weight loss when compared to placebo, along with a $31 \%$ reduction in progression to diabetes. ${ }^{16}$ This effect was more pronounced with higher BMI and younger age.

The BIGuanides and Prevention of Risks in Obesity (BIGPRO1) study examined the effect of metformin on weight and insulin resistance. Among the 324 subjects with upper-body obesity, metformin induced a significant weight loss (1-2 kg) with significant improvement of metabolic syndrome parameters after one year of treatment. ${ }^{98}$

These results suggest that metformin is a viable therapeutic option in obese or overweight patients at risk for diabetes and the metabolic syndrome, and it is the preferred agent in treatment of diabetes as well as polyscysitc ovaries syndrome in obese subjects. ${ }^{99}$

The most common side-effect observed with metformin is diarrhea and gastro-intestinal disturbances. Metformin use should be avoided in patients with renal failure, in view of the increased risk of lactic acidosis with biguanides in this patient population.

\section{Exenatide $\left(\right.$ Byetta $\left.^{\circledR}\right)$}

Exenatide is a long acting synthetic glucagon-like polypeptide 1 (GLP1) receptor agonist that acts through glucose-dependent stimulation of insulin secretion, suppression of glucagon secretion and slowing of gastric emptying, leading to an improvement in glycemic control in diabetic patients and a modest weight loss through decreased food intake. ${ }^{100}$

In a 30-week study of 336 adults with type 2 diabetes on metformin, treatment with Exenatide was associated with significant dose-dependent weight loss up to $2.8 \mathrm{~kg}$ with $10 \mu \mathrm{g}$ subcutaneous twice daily compared to placebo. ${ }^{101}$ Similar findings were obtained in two other 30-week trials of exenatide in patients treated with sulfonylureas and metformin and sulfonylureas alone. ${ }^{102,103}$ An open-label extension of exenatide treatment in two of the trials revealed a significant weight loss of $4.4 \mathrm{~kg}$ and $5.3 \mathrm{~kg}$ at 82 weeks. ${ }^{104,105}$

Unlike most of the weight loss trials, diet and exercise were not component of the therapy in exenatide trials, and all of the weight loss described was attributed to the medication.

Nausea is the most common side-effect of exenatide.

\section{Pramlintide $\left(\right.$ Symlin $\left.^{\circledR}\right)$}

Pramlintide is a synthetic analog of amylin, which is a peptide co-secreted with insulin by pancreatic beta-cells in response to food intake. Amylin complements the role of insulin in regulating post-meal glucose, suppresses post meal glucagon secretion, slows gastric emptying and decreases food intake. Pramlintide is approved for treatment of type 1 and type 2 diabetes with meal time insulin and has been associated with decreased food intake and weight loss in clinical trials. ${ }^{106}$

In a double-blind, placebo-controlled, multicenter study, six hundred fifty-one patients with type 1 diabetes were randomized to mealtime injections of placebo or pramlintide, in addition to their insulin therapy. At 1 year, addition of pramlintide ( $60 \mu \mathrm{g}$ with meals) to insulin led to a significant reduction in body weight $(-0.4 \mathrm{~kg}$ weight loss versus $+0.8 \mathrm{~kg}$ weight gain in body weight in the placebo group). ${ }^{107}$

Pramlintide is particularly interesting in the treatment of diabetic patients who experience weight gain associated with the use of insulin. Nausea is a common side-effect of pramlintide.

\section{Experimental drugs}

Multiple novel therapeutic agents for obesity are being currently developed and include either peripherally produced peptides or centrally acting neurotransmitters and receptors involved in appetite regulation.

\section{Combination therapy}

Topiramate/Phentermine $\left(\right.$ Qnexa $\left.^{\circledR}\right)$

Phase III trials with a novel obesity agent combining phentermine and topiramate $\left(\right.$ Qnexa $\left.{ }^{\circledR}\right)$ were recently completed and revealed promising results. As the two agents induce weight reduction via different mechanisms, topiramate through GABA and other agonists properties increasing satiety, and phentermine through decreasing appetite, an additive effect of the combination was expected and was observed in the three pivotal phase III trials of the drug. An average of $37 \mathrm{lbs}$ (14.7\% of body weight) was achieved at 56 weeks of therapy with Qnexa in the EQUIP and CONQUER study with 69\% completion rate, positive tolerability and favorable metabolic and safety profile. ${ }^{108}$

\section{Bupropion SR/Naltrxone SR (Contrave ${ }^{\circledR}$ )}

Contrave $^{\circledR}$ is another investigational medication for the treatment of obesity completing currently four phase III clinical trials. While bupropion is believed to help initiate weight loss, the combined naltrexone may sustain the weight reduction by blocking the opioid receptors and inhibiting the reinforcing and rewarding aspect of addictive substances as observed in alcohol abstinence. Two of the four COntrove Obesity Research (COR) trials results announced in October 2009 
revealed that approximately $25 \%-33 \%$ of obese individuals lost $10 \%$ or more of their body weight and $12 \%$ to $16 \%$ lost at least $15 \%$ of body at 56 weeks of therapy with Contrave, with demonstrated significant improvements in markers of cardiometabolic risk including waist circumference, HDL and triglycerides. ${ }^{109}$

\section{5-HTIBR and 5-HT2CR selective agonsits}

As mentioned earlier, serotoninergic pathway plays a very well known role in appetite suppression. The therapeutic limitations with earlier potent serotonergic agents such as D-fenfluramine were the nonselective effect on 5-HT receptors causing different side-effects including valvular heart disease. Recently, central 5-HT1BRs and 5-HT2CRs receptors have been identified as the 5-HT receptors that are specifically involved in body weight and food intake control. Pharamceutical research is currently working on developing serotonergic agents that specifically target the appetite regulation pathway via direct interaction with 5-HT2cRs and 5-HT1BRs on arcuate POMC and AgRP/ NPY neurons, respectively, with a resulting activation of the downstream melanocortin system. Lorcacerin is a new selective 5-HT2cRs and 5-HT1BRs agonist that is currently in phase III trial with three major clinical tials enrolling around 7800 patients. The results of the first trial, the BLOOM (Behavioral modification and Lorcaserin for Overweight and Obesity Management) were presented at the 69th Scientific Sessions of the American Diabetes Association in June 2009 with an induced average weight loss of $5.8 \%$ of body weight, or $12.7 \mathrm{lb}$, in the lorcaserin group, compared to $2.2 \%$, or 4.7 $\mathrm{lb}$, for placebo, in addition to favorable metabolic effect and absence of associated psychiatric side-effects or valvular disease. The BLOSSOM (Behavioral modification and LOrcaserin Second Study for Obesity Management) trial results were more recently announced revealing an average weight loss of $17.0 \mathrm{lb}$ or $7.9 \%$ of body weight with lorcacerin therapy at one year, compared to $8.7 \mathrm{lb}$ or $3.9 \%$ for placebo and an achieved average weight loss of $5.9 \%$ of body weight at 2 years compared to $2.8 \%$ for placebo. ${ }^{110}$

\section{Ghrelin}

Ghrelin is a hormone secreted by the gastrointestinal tract endocrine cells, particularly in situations of energy insufficiency or deprivation. It is believed that ghrelin plays a major role in feeding control regulation by its potential direct effect on central nervous system. Stimulating appetite, lowering energy expenditure, shifting diet preference towards food rich in fat and increasing the rewarding value of food are all potential mechanisms by which ghrelin leads to increased body weight and increased adiposity. ${ }^{111,112}$

In humans, ghrelin levels are generally low in obese individuals and increase during weight reduction, potentially contributing to weight regain observed typically after initial weight loss. ${ }^{113}$ Interestingly ghrelin levels are suppressed after bariatric surgery probably playing a role in the weight reduction observed after the procedure. ${ }^{113}$ On the other hand, ghrelin levels have been observed to be very elevated in Prader-Willi Syndrome playing very likely a causative role in the hyperphagia observed in these patients. ${ }^{114}$

Multiple animal studies aiming to inactivate normal ghrelin signaling pathways have led to significant weight reduction with specifically decreased adipose mass along with inconsistent effect on energy expenditure and food intake. Inhibition of ghrelin is currently being studied and developed as a potential weight-reducing agent. ${ }^{115}$

\section{Leptin}

Leptin is one of the peptides secreted by adipose tissue with a central effect on hypothalamic appetite center. Historically, mice lacking leptin synthesis and activity (ob/ob) are massively obese and rare cases of humans with leptin deficiency are reported to have morbid obesity since childhood and responded dramatically to leptin infusion. ${ }^{116}$ The majority of obese subjects have high plasma levels of leptin suggesting a probable leptin resistance that could hypothetically be overcome by high dose leptin. In a randomized, double-blind, placebo-controlled, multicenter trial, 54 lean and 73 obese subjects were randomized to varying doses of recombinant methionyl human leptin subcutaneous injection daily or placebo for 4 weeks with extension of treatment to 20 weeks for obese participants. ${ }^{117}$ Leptin induced significant weight loss in a dose-dependent fashion in all subjects at 4 weeks and in obese subjects at 24 weeks. Mean weight loss at 24 weeks ranged from $-0.7 \mathrm{~kg}$ for the $0.01 \mathrm{mg} / \mathrm{kg}$ dose to $-7.1 \mathrm{~kg}$ for the $0.30 \mathrm{mg} / \mathrm{kg}$ dose. In another randomized, double-blind, placebo-controlled study of 284 overweight or obese patients, leptin injections at $10 \mathrm{mg}$ twice a day did not lead to more weight loss at 12 weeks compared to placebo. ${ }^{118}$

Leptin concentrations were observed to decrease, along with thyroid hormone levels, during fasting and energy restriction states, suggesting that leptin administration can play a role in regulating energy expenditure in these cases. To explore this hypothesis, a randomized, double-blind, placebo-controlled study was conducted in 22 overweight men who were randomized to weekly injection of pegylated recombinant leptin (PEG-OB) or placebo while on a very 
low caloric diet for 46 days. ${ }^{119}$ Treatment with PEG-OB led to significant additional weight loss $(14.6 \mathrm{~kg}$ compared to $11.8 \mathrm{~kg}$ in placebo group) along with a reduction in appetite. Another small study suggested that the decreased energy expenditure associated with weight loss can be partially reversed by leptin treatment, conferring to leptin a potential role in preventing weight regain in maintenance phase of weight loss. ${ }^{120}$

In summary, because of this resistance, even high doses of leptin have produced only modest success at reducing body weight in general obesity. However studies suggest that leptin may be effective in enhancing the maintenance of weight loss achieved by either lifestyle modifications or other drug therapies.

Leptin seems also to improve glycemic control and decrease triglycerides level in patients with lipodystrophy and leptin deficiency. ${ }^{121}$

\section{Peptide $Y Y$}

Peptide YY 3-36 is another appetite-regulating hormone under investigation for obesity treatment. It is derived from the gastro-intestinal peptide PYY and was shown to decrease appetite and food intake in normal subjects by modulating appetite circuits in the hypothalamus. ${ }^{122}$

The effects of PYY infusion on appetite and food intake was assessed in a study of 12 obese and 12 lean subjects in a double-blind, placebo-controlled, crossover study. PYY infusion caused a significant $30 \%$ decrease in food intake in both lean and obese subjects. Endogenous fasting and postprandial levels of PYY were significantly lower in obese subjects suggesting that, unlike leptin, obese patients were not resistant to the anorectic effects of PYY and that PYY deficiency could play a role in the pathophysiology of obesity. ${ }^{123}$ Intranasal peptide YY (3-36) given before meals in a recent study of 133 obese adults did not achieve significant higher weight reduction when compared to placebo because of a very high discontinuation of the drug secondary to associated nausea. ${ }^{124}$

\section{Oxyntomodulin}

Oxyntomodulin is another gastro-intestinal peptide secreted in response to meals and playing a role in appetite suppression.

In a randomized, double-blind trial, self-injection of oxyntomodulin before meals for 4 weeks induced a significant weight loss of $2.3 \mathrm{~kg}$ in the treatment group compared with $0.5 \mathrm{~kg}$ in the placebo group, along with a significant decrease in energy intake in the oxyntomodulin group. ${ }^{125}$

\section{Melanocortin 4-receptor agonists}

The MC4-R hypothalamic signaling pathway plays a major role in feeding behavioral control and is regulated by leptin responsive endogenous agonists and antagonists. Mutations of MC4-R are the most common causes of human monogenic obesity and are thought to account for $5 \%$ to $10 \%$ of common morbid obesity. ${ }^{126}$ In animal models, MC4-R absence leads to adult onset obesity. ${ }^{127}$ Moreover, MC4-R deficient mice are not able to respond to high fat diets by increasing thermogenesis and physical activity, suggesting a potential role of the melanocortin system in energy homeostasis. ${ }^{128}$

Numerous MC4-R agonists are being developed as potential targets for obesity therapy. ${ }^{129-131}$

\section{Other experimental drugs}

Several other medications are at different stages of investigation for their ability to induce weight loss and include: tesofensine (sympathomimietic), SIRT 1, peptide analog of growth hormone fragnment hGH 177-191, somatostatin, Axokine, Neuropeptide Y Receptor antagonists, pancreatic lipase inhibitor (cetilistat), cholecystokinin, beta3 adrenergic receptors agonists, and combination of anti-obesity drugs, in addition to multiple experimental drugs in early phase of development. ${ }^{132}$

\section{Clinical viewpoints}

When prescribing medications for obesity, physicians should be familiar with certain aspects of weight reducing pharmacologic agents:

- The pharmacologic agents should always be given in conjunction with diet and exercise as therapeutic effect observed in the trials applied to patients who were following lifestyle changes and having close medical follow-ups. The efficacy of medication alone would probably be reduced by at least $50 \%$ if not combined to behavioral changes. ${ }^{59}$

- The efficacy of the medication can be measured by the amount of weight loss and the improvement of comorbidities. Responders will usually lose at least $2 \mathrm{~kg}$ during the first month of therapy and 5\% of body weight at 3 to 6 months of therapy. Patients who do not respond within 4 weeks of therapy are unlikely to benefit from the medication and should not be exposed to unnecessary prolonged therapy.

- The efficacy of weight reducing agents is limited by a maximal weight loss that usually peaks at 6 to 12 months and generally does not exceed $10 \%$ of body weight. However, as mentioned earlier, such a moderate effect would lead to favorable metabolic outcomes as observed in most of the clinical trials. 
- Patients will typically start regain weight during the second year of therapy, though to a lesser degree than patients on placebo, fact that is believed to be related to decreased body energy expenditure after weight loss.

- Long-term compliance with lifestyle changes and pharmacotherapy has been suboptimal as reflected by the consistent high drop-out percentage in both placebo and intervention arms of the trials.

- The weight reducing agents work when taken and their beneficial effect subsides after discontinuation of therapy. The longest trial duration was 2 years for sibutramine and 4 years for orlistat. It is therefore unclear how to manage patients after 2 or 4 years of therapy.

- It is of extreme importance to discuss the expected effects and side-effects of pharmacotherapy with obese patients to avoid unnecessary frustrations and discontinuation of therapy. Patients treated with weight reducing agents should be followed regularly to encourage compliance, assess efficacy and monitor side effects of therapy.

\section{Conclusion}

Despite the rising tide of the obesity epidemic worldwide with its enormous impact on morbidity and mortality together with the massive healthcare cost, only a few medical therapeutic options are currently available for long-term weight loss, that have been shown to be safe and effective. These agents include orlistat and sibutramine. With these agents, however, weight loss is modest and long-term beneficial effects on cardiovascular end-points remain to be established.

The gigantic nature of this obesity epidemic has led to deeper understanding, over the past decades, of appetite regulation and weight control pathways, opening the horizons to many potential drugs for assisted weight loss. Obesity is currently one of the most active research fields with the hope that novel therapeutic agents can help curving the growing pandemic of obesity and its associated comorbidities.

\section{Disclosures}

The authors declare no conflicts of interest.

\section{References}

1. WHO website. http://www.who.int/mediacentre/factsheets/fs311/en/.

2. Flegal KM, Carroll MD, Ogden CL, Johnson CL. Prevalence and trends in obesity among US adults, 1999-2000. JAMA. 2002;288(14): 1723-1727.

3. Ogden CL, Carroll MD, Curtin LR, McDowell MA, Tabak CJ, Flegal KM. Prevalence of overweight and obesity in the United States, 1999-2004. JAMA. 2006;295(13):1549-1555.

4. Sturm R. Increases in clinically severe obesity in the United States, 1986-2000. Arch Intern Med. 2003;163(18):2146-2148.
5. Hubert HB. The importance of obesity in the development of coronary risk factors and disease: the epidemiologic evidence. Annu Rev Public Health. 1986;7:493-502.

6. Adams KF, Schatzkin A, Harris TB, et al. Overweight, obesity, and mortality in a large prospective cohort of persons 50 to 71 years old. N Engl J Med. 2006;355(8):763-778.

7. Thompson D, Edelsberg J, Colditz GA, Bird AP, Oster G. Lifetime health and economic consequences of obesity. Arch Intern Med. 1999;159(18):2177-2183.

8. Wolf AM, Colditz GA. The cost of obesity: the US perspective. Pharmacoeconomics. 1994;5(Suppl 1):34-37.

9. Bouchard C, Perusse L. Genetics of obesity. Annu Rev Nutr. 1993;13:337-354.

10. Clinical Guidelines on the Identification, Evaluation, and Treatment of Overweight and Obesity in Adults - The Evidence Report. National Institutes of Health. Obes Res. Sep; 1998/11/14:51S-209S. http://www. ncbi.nlm.nih.gov/entrez/query.fcgi?cmd=Retrieve \&db=PubMed\&dop $\mathrm{t}=$ Citation\&list_uids=9813653, 6 Suppl 2.

11. Lee A, Morley JE. Metformin decreases food consumption and induces weight loss in subjects with obesity with type II non-insulin-dependent diabetes. Obes Res.1998;6(1):47-53.

12. Karam J, McFarlane S. Secondary causes of obesity. Therapy. 2007;4(5):641-650.

13. Snow V, Barry P, Fitterman N, Qaseem A, Weiss K. Pharmacologic and surgical management of obesity in primary care: a clinical practice guideline from the American College of Physicians. Ann Intern Med. 2005;142(7):525-531.

14. National Institutes of Health, National Heart, Lung, and Blood Institute. The Practical Guide: Identification, Evaluation, and Treatment of Overweight and Obesity in Adults. NIH publication number 02-4084. 2002.

15. UKPDS Task Force website. www.ahrq.gov/clinic/USpstf/uspsobes.htm.

16. Knowler WC, Barrett-Connor E, Fowler SE, et al. Reduction in the incidence of type 2 diabetes with lifestyle intervention or metformin. N Engl J Med. 2002;346(6):393-403.

17. Goldstein DJ. Beneficial health effects of modest weight loss. Int J Obes Relat Metab Disord. 1992;16(6):397-415.

18. Pasanisi F, Contaldo F, de Simone G, Mancini M. Benefits of sustained moderate weight loss in obesity. Nutr Metab Cardiovasc Dis. 2001;11(6):401-406.

19. Heilbronn LK, de Jonge L, Frisard MI, et al. Effect of 6-month calorie restriction on biomarkers of longevity, metabolic adaptation, and oxidative stress in overweight individuals: a randomized controlled trial. JAMA. 2006;295(13):1539-1548.

20. Metz JA, Stern JS, Kris-Etherton P, et al. A randomized trial of improved weight loss with a prepared meal plan in overweight and obese patients: impact on cardiovascular risk reduction. Arch Intern Med. 2000;160(14):2150-2158.

21. Arora SK, McFarlane SI. The case for low carbohydrate diets in diabetes management. Nutr Metab (Lond). 2005;2:16.

22. Dansinger ML, Gleason JA, Griffith JL, Selker HP, Schaefer EJ. Comparison of the Atkins, Ornish, Weight Watchers, and Zone diets for weight loss and heart disease risk reduction: a randomized trial. JAMA. 2005;293(1):43-53.

23. Gardner CD, Kiazand A, Alhassan S, et al. Comparison of the Atkins, Zone, Ornish, and LEARN diets for change in weight and related risk factors among overweight premenopausal women: the A TO Z Weight Loss Study: a randomized trial. JAMA. 2007;297(9): 969-977.

24. Garrow JS, Summerbell CD. Meta-analysis: effect of exercise, with or without dieting, on the body composition of overweight subjects. Eur J Clin Nutr. 1995;49(1):1-10.

25. Jakicic JM, Marcus BH, Gallagher KI, Napolitano M, Lang W. Effect of exercise duration and intensity on weight loss in overweight, sedentary women: a randomized trial. JAMA. 2003;290(10): $1323-1330$. 
26. Mathus-Vliegen EM. Long-term maintenance of weight loss with sibutramine in a GP setting following a specialist guided very-low-calorie diet: a double-blind, placebo-controlled, parallel group study. Eur J Clin Nutr. 2005;59 Suppl 1:S31-S38; discussion S39.

27. Miller WC, Koceja DM, Hamilton EJ. A meta-analysis of the past 25 years of weight loss research using diet, exercise or diet plus exercise intervention. Int J Obes Relat Metab Disord. 1997;21(10):941-947.

28. Gilliat-Wimberly M, Manore MM, Woolf K, Swan PD, Carroll SS. Effects of habitual physical activity on the resting metabolic rates and body compositions of women aged 35 to 50 years. J Am Diet Assoc. 2001;101(10):1181-1188.

29. Chambliss HO. Exercise duration and intensity in a weight-loss program. Clin J Sport Med. 2005;15(2):113-115.

30. Jakicic JM, Winters C, Lang W, Wing RR. Effects of intermittent exercise and use of home exercise equipment on adherence, weight loss, and fitness in overweight women: a randomized trial. JAMA. 1999;282(16):1554-1560.

31. Lin XM, Li B, Du YH, Xiong J, Sun P. Systematic evaluation of therapeutic effect of acupuncture for treatment of simple obesity. Zhongguo Zhen Jiu. 2009;29(10):856-860.

32. Cho SH, Lee JS, Thabane L, Lee J. Acupuncture for obesity: a systematic review and meta-analysis. Int J Obes (Lond). 2009;33(2):183-196.

33. Hsu CH, Wang CJ, Hwang KC, Lee TY, Chou P, Chang HH. The effect of auricular acupuncture in obese women: a randomized controlled trial. $J$ Womens Health (Larchmt). 2009;18(6):813-818.

34. Zhi J, Melia AT, Guerciolini R, et al. Retrospective populationbased analysis of the dose-response (fecal fat excretion) relationship of orlistat in normal and obese volunteers. Clin Pharmacol Ther. 1994;56(1):82-85.

35. Carriere F, Renou C, Ransac S, et al. Inhibition of gastrointestinal lipolysis by Orlistat during digestion of test meals in healthy volunteers. Am J Physiol Gastrointest Liver Physiol. 2001;281(1):G16-G28.

36. Padwal R, Li SK, Lau DC. Long-term pharmacotherapy for obesity and overweight. Cochrane Database Syst Rev. 2004(3):CD004094.

37. Ullrich A, Erdmann J, Margraf J, Schusdziarra V. Impact of carbohydrate and fat intake on weight-reducing efficacy of orlistat. Aliment Pharmacol Ther. 2003;17(8):1007-1013.

38. Torgerson JS, Hauptman J, Boldrin MN, Sjostrom L. XENical in the prevention of diabetes in obese subjects (XENDOS) study: a randomized study of orlistat as an adjunct to lifestyle changes for the prevention of type 2 diabetes in obese patients. Diabetes Care. 2004;27(1): $155-161$.

39. Li Z, Maglione M, Tu W, et al. Meta-analysis: pharmacologic treatment of obesity. Ann Intern Med. 2005;142(7):532-546.

40. Sjostrom L, Rissanen A, Andersen T, et al. Randomised placebocontrolled trial of orlistat for weight loss and prevention of weight regain in obese patients. European Multicentre Orlistat Study Group. Lancet. 1998;352(9123):167-172.

41. Chanoine JP, Hampl S, Jensen C, Boldrin M, Hauptman J. Effect of orlistat on weight and body composition in obese adolescents: a randomized controlled trial. JAMA. 2005;293(23):2873-2883.

42. Hill JO, Hauptman J, Anderson JW, et al. Orlistat, a lipase inhibitor, for weight maintenance after conventional dieting: a 1-y study. Am J Clin Nutr. 1999;69(6):1108-1116.

43. Hutton B, Fergusson D. Changes in body weight and serum lipid profile in obese patients treated with orlistat in addition to a hypocaloric diet: a systematic review of randomized clinical trials. Am J Clin Nutr. 2004;80(6):1461-1468.

44. Tonstad S, Pometta D, Erkelens DW, et al. The effect of the gastrointestinal lipase inhibitor, orlistat, on serum lipids and lipoproteins in patients with primary hyperlipidaemia. Eur J Clin Pharmacol. 1994;46(5):405-410.

45. Lindgarde F. The effect of orlistat on body weight and coronary heart disease risk profile in obese patients: the Swedish Multimorbidity Study. J Intern Med. 2000;248(3):245-254.

46. Davidson MH, Hauptman J, DiGirolamo M, et al. Weight control and risk factor reduction in obese subjects treated for 2 years with orlistat: a randomized controlled trial. JAMA. 1999;281(3):235-242.
47. Hauptman J, Lucas C, Boldrin MN, Collins H, Segal KR. Orlistat in the long-term treatment of obesity in primary care settings. Arch Fam Med. 2000;9(2):160-167.

48. Kelley DE, Bray GA, Pi-Sunyer FX, et al. Clinical efficacy of orlistat therapy in overweight and obese patients with insulin-treated type 2 diabetes: A 1-year randomized controlled trial. Diabetes Care. 2002;25(6):1033-1041.

49. Hollander PA, Elbein SC, Hirsch IB, et al. Role of orlistat in the treatment of obese patients with type 2 diabetes. A 1-year randomized double-blind study. Diabetes Care. 1998;21(8):1288-1294.

50. Cavaliere H, Floriano I, Medeiros-Neto G. Gastrointestinal side effects of orlistat may be prevented by concomitant prescription of natural fibers (psyllium mucilloid). Int J Obes Relat Metab Disord. 2001;25(7):1095-1099.

51. FDA website. www.fda.gov/Drugs/DrugsSafety/PostMarket DrugsSafety.

52. Barkeling B, Elfhag K, Rooth P, Rossner S. Short-term effects of sibutramine (Reductil) on appetite and eating behaviour and the long-term therapeutic outcome. Int $J$ Obes Relat Metab Disord. 2003;27(6):693-700.

53. Hansen DL, Toubro S, Stock MJ, Macdonald IA, Astrup A. Thermogenic effects of sibutramine in humans. Am J Clin Nutr. 1998;68(6):1180-1186.

54. Smith IG, Goulder MA. Randomized placebo-controlled trial of longterm treatment with sibutramine in mild to moderate obesity. $J$ Fam Pract. 2001;50(6):505-512.

55. Wirth A, Krause J. Long-term weight loss with sibutramine: a randomized controlled trial. JAMA. 2001;286(11):1331-1339.

56. Apfelbaum M, Vague P, Ziegler O, Hanotin C, Thomas F, Leutenegger E. Long-term maintenance of weight loss after a very-low-calorie diet: a randomized blinded trial of the efficacy and tolerability of sibutramine. Am J Med. 1999;106(2):179-184.

57. Bray GA, Blackburn GL, Ferguson JM, et al. Sibutramine produces dose-related weight loss. Obes Res. 1999;7(2):189-198.

58. James WP, Astrup A, Finer N, et al. Effect of sibutramine on weight maintenance after weight loss: a randomised trial. STORM Study Group. Sibutramine Trial of Obesity Reduction and Maintenance. Lancet. 2000;356(9248):2119-2125.

59. Wadden TA, Berkowitz RI, Womble LG, et al. Randomized trial of lifestyle modification and pharmacotherapy for obesity. $N$ Engl J Med. 2005;353(20):2111-2120

60. McNulty SJ, Ur E, Williams G. A randomized trial of sibutramine in the management of obese type 2 diabetic patients treated with metformin. Diabetes Care. 2003;26(1):125-131.

61. Vettor R, Serra R, Fabris R, Pagano C, Federspil G. Effect of sibutramine on weight management and metabolic control in type 2 diabetes: a metaanalysis of clinical studies. Diabetes Care. 2005;28(4):942-949.

62. Norris SL, Zhang X, Avenell A, et al. Efficacy of pharmacotherapy for weight loss in adults with type 2 diabetes mellitus: a meta-analysis. Arch Intern Med. 2004;164(13):1395-1404.

63. Arterburn DE, Crane PK, Veenstra DL. The efficacy and safety of sibutramine for weight loss: a systematic review. Arch Intern Med. 2004;164(9):994-1003.

64. Sramek JJ, Leibowitz MT, Weinstein SP, et al. Efficacy and safety of sibutramine for weight loss in obese patients with hypertension well controlled by beta-adrenergic blocking agents: a placebo-controlled, double-blind, randomised trial. J Hum Hypertens. 2002;16(1):13-19.

65. Kim SH, Lee YM, Jee SH, Nam CM. Effect of sibutramine on weight loss and blood pressure: a meta-analysis of controlled trials. Obes Res. 2003;11(9):1116-1123.

66. McMahon FG, Fujioka K, Singh BN, et al. Efficacy and safety of sibutramine in obese white and African American patients with hypertension: a 1-year, double-blind, placebo-controlled, multicenter trial. Arch Intern Med. 2000;160(14):2185-2191.

67. McMahon FG, Weinstein SP, Rowe E, Ernst KR, Johnson F, Fujioka K. Sibutramine is safe and effective for weight loss in obese patients whose hypertension is well controlled with angiotensin-converting enzyme inhibitors. J Hum Hypertens. 2002;16(1):5-11. 
68. Scholze J, Grimm E, Herrmann D, Unger T, Kintscher U. Optimal treatment of obesity-related hypertension: the Hypertension-Obesity-Sibutramine (HOS) study. Circulation. 2007;115(15):1991-1998.

69. Berkowitz RI, Fujioka K, Daniels SR, et al. Effects of sibutramine treatment in obese adolescents: a randomized trial. Ann Intern Med. 2006;145(2):81-90.

70. Godoy-Matos A, Carraro L, Vieira A, et al. Treatment of obese adolescents with sibutramine: a randomized, double-blind, controlled study. J Clin Endocrinol Metab. 2005;90(3):1460-1465.

71. Bach DS, Rissanen AM, Mendel CM, et al. Absence of cardiac valve dysfunction in obese patients treated with sibutramine. Obes Res. 1999;7(4):363-369.

72. Zannad F, Gille B, Grentzinger A, et al. Effects of sibutramine on ventricular dimensions and heart valves in obese patients during weight reduction. Am Heart J. 2002;144(3):508-515.

73. Wadden TA, Berkowitz RI, Womble LG, Sarwer DB, Arnold ME, Steinberg CM. Effects of sibutramine plus orlistat in obese women following 1 year of treatment by sibutramine alone: a placebo-controlled trial. Obes Res. 2000;8(6):431-437.

74. Aydin N, Topsever P, Kaya A, Karasakal M, Duman C, Dagar A. Orlistat, sibutramine, or combination therapy: which performs better on waist circumference in relation with body mass index in obese patients? Tohoku J Exp Med. 2004;202(3):173-180.

75. Gokcel A, Gumurdulu Y, Karakose H, et al. Evaluation of the safety and efficacy of sibutramine, orlistat and metformin in the treatment of obesity. Diabetes Obes Metab. 2002;4(1):49-55.

76. Sari R, Balci MK, Cakir M, Altunbas H, Karayalcin U. Comparison of efficacy of sibutramine or orlistat versus their combination in obese women. Endocr Res. 2004;30(2):159-167.

77. Cota D, Marsicano G, Tschop M, et al. The endogenous cannabinoid system affects energy balance via central orexigenic drive and peripheral lipogenesis. J Clin Invest. 2003;112(3):423-431.

78. Van Gaal LF, Rissanen AM, Scheen AJ, Ziegler O, Rossner S. Effects of the cannabinoid-1 receptor blocker rimonabant on weight reduction and cardiovascular risk factors in overweight patients: 1-year experience from the RIO-Europe study. Lancet. 2005;365(9468):1389-1397.

79. Despres JP, Golay A, Sjostrom L. Effects of rimonabant on metabolic risk factors in overweight patients with dyslipidemia. $N$ Engl J Med. 2005;353(20):2121-2134.

80. Scheen AJ, Finer N, Hollander P, Jensen MD, Van Gaal LF. Efficacy and tolerability of rimonabant in overweight or obese patients with type 2 diabetes: a randomised controlled study. Lancet. 2006;368(9548):1660-1672.

81. Pi-Sunyer FX, Aronne LJ, Heshmati HM, Devin J, Rosenstock J. Effect of rimonabant, a cannabinoid-1 receptor blocker, on weight and cardiometabolic risk factors in overweight or obese patients: RIO-North America: a randomized controlled trial. JAMA. 2006;295(7):761-775.

82. Curioni C, Andre C. Rimonabant for overweight or obesity. Cochrane Database Syst Rev. 2006(4):CD006162.

83. Rosenstock J, Hollander P, Chevalier S, Iranmanesh A. SERENADE: the Study Evaluating Rimonabant Efficacy in Drug-naive Diabetic Patients: effects of monotherapy with rimonabant, the first selective CB1 receptor antagonist, on glycemic control, body weight, and lipid profile in drug-naive type 2 diabetes. Diabetes Care. 2008;31(11):2169-2176.

84. Nissen SE, Nicholls SJ, Wolski K, et al. Effect of rimonabant on progression of atherosclerosis in patients with abdominal obesity and coronary artery disease: the STRADIVARIUS randomized controlled trial. JAMA. 2008;299(13):1547-1560.

85. Christensen R, Kristensen PK, Bartels EM, Bliddal H, Astrup A. Efficacy and safety of the weight-loss drug rimonabant: a meta-analysis of randomised trials. Lancet. 2007;370(9600):1706-1713.

86. Kernan WN, Viscoli CM, Brass LM, et al. Phenylpropanolamine and the risk of hemorrhagic stroke. $N$ Engl J Med. 2000;343(25):1826-1832.

87. Weissman NJ, Tighe JF, Jr., Gottdiener JS, Gwynne JT. An assessment of heart-valve abnormalities in obese patients taking dexfenfluramine, sustained-release dexfenfluramine, or placebo. Sustained-Release Dexfenfluramine Study Group. $N$ Engl J Med. 1998;339(11):725-732
88. Choi HK, Atkinson K, Karlson EW, Curhan G. Obesity, weight change, hypertension, diuretic use, and risk of gout in men: the health professionals follow-up study. Arch Intern Med. 2005;165(7): 742-748.

89. Haddock CK, Poston WS, Dill PL, Foreyt JP, Ericsson M. Pharmacotherapy for obesity: a quantitative analysis of four decades of published randomized clinical trials. Int J Obes Relat Metab Disord. 2002;26(2):262-273.

90. Munro JF, MacCuish AC, Wilson EM, Duncan LJ. Comparison of continuous and intermittent anorectic therapy in obesity. $\mathrm{Br} \mathrm{Med} J$. 1968;1(5588):352-354.

91. Goldstein DJ, Rampey AH Jr, Enas GG, Potvin JH, Fludzinski LA, Levine LR. Fluoxetine: a randomized clinical trial in the treatment of obesity. Int J Obes Relat Metab Disord. 1994;18(3):129-135.

92. Goldstein DJ, Rampey AH Jr, Roback PJ, et al. Efficacy and safety of long-term fluoxetine treatment of obesity - maximizing success. Obes Res. 1995;3 Suppl 4:481S-490S.

93. Wadden TA, Bartlett SJ, Foster GD, et al. Sertraline and relapse prevention training following treatment by very-low-calorie diet: a controlled clinical trial. Obes Res. 1995;3(6):549-557.

94. Anderson JW, Greenway FL, Fujioka K, Gadde KM, McKenney J, O’Neil PM. Bupropion SR enhances weight loss: a 48-week doubleblind, placebo-controlled trial. Obes Res. 2002;10(7):633-641.

95. Shapira NA, Goldsmith TD, McElroy SL. Treatment of binge-eating disorder with topiramate: a clinical case series. J Clin Psychiatry. 2000;61(5):368-372.

96. McElroy SL, Arnold LM, Shapira NA, et al. Topiramate in the treatment of binge eating disorder associated with obesity: a randomized, placebo-controlled trial. Am J Psychiatry. 2003;160(2): 255-261.

97. Gadde KM, Franciscy DM, Wagner HR 2nd, Krishnan KR. Zonisamide for weight loss in obese adults: a randomized controlled trial. JAMA. 2003;289(14):1820-1825.

98. Fontbonne A, Charles MA, Juhan-Vague I, et al. The effect of metformin on the metabolic abnormalities associated with upper-body fat distribution. BIGPRO Study Group. Diabetes Care. 1996;19(9): 920-926.

99. Pasquali R, Gambineri A, Biscotti D, et al. Effect of long-term treatment with metformin added to hypocaloric diet on body composition, fat distribution, and androgen and insulin levels in abdominally obese women with and without the polycystic ovary syndrome. $J$ Clin Endocrinol Metab. 2000;85(8):2767-2774.

100. Poon T, Nelson P, Shen L, et al. Exenatide improves glycemic control and reduces body weight in subjects with type 2 diabetes: a doseranging study. Diabetes Technol Ther. 2005;7(3):467-477.

101. DeFronzo RA, Ratner RE, Han J, Kim DD, Fineman MS, Baron AD. Effects of exenatide (exendin-4) on glycemic control and weight over 30 weeks in metformin-treated patients with type 2 diabetes. Diabetes Care. 2005;28(5):1092-1100.

102. Kendall DM, Riddle MC, Rosenstock J, et al. Effects of exenatide (exendin-4) on glycemic control over 30 weeks in patients with type 2 diabetes treated with metformin and a sulfonylurea. Diabetes Care. 2005;28(5):1083-1091.

103. Buse JB, Henry RR, Han J, Kim DD, Fineman MS, Baron AD. Effects of exenatide (exendin-4) on glycemic control over 30 weeks in sulfonylurea-treated patients with type 2 diabetes. Diabetes Care. 2004;27(11):2628-2635.

104. Blonde L, Klein EJ, Han J, et al. Interim analysis of the effects of exenatide treatment on $\mathrm{A} 1 \mathrm{C}$, weight and cardiovascular risk factors over 82 weeks in 314 overweight patients with type 2 diabetes. Diabetes Obes Metab. 2006;8(4):436-447.

105. Ratner RE, Maggs D, Nielsen LL, et al. Long-term effects of exenatide therapy over 82 weeks on glycaemic control and weight in over-weight metformin-treated patients with type 2 diabetes mellitus. Diabetes Obes Metab. 2006;8(4):419-428.

106. Hollander P, Maggs DG, Ruggles JA, et al. Effect of pramlintide on weight in overweight and obese insulin-treated type 2 diabetes patients. Obes Res. 2004;12(4):661-668. 
107. Ratner RE, Dickey R, Fineman M, et al. Amylin replacement with pramlintide as an adjunct to insulin therapy improves long-term glycaemic and weight control in Type 1 diabetes mellitus: a 1-year, randomized controlled trial. Diabet Med. 2004;21(11):1204-1212.

108. Vivus website. www.vivus.com

109. Orexigen website. www.orexigen.com

110. Arena Pharm website. http://wwwials .arenapharm.com/wt/page/ lho.html

111. Tschop M, Smiley DL, Heiman ML. Ghrelin induces adiposity in rodents. Nature. 2000;407(6806):908-913.

112. Wren AM, Small CJ, Abbott CR, et al. Ghrelin causes hyperphagia and obesity in rats. Diabetes. 2001;50(11):2540-2547.

113. Cummings DE, Weigle DS, Frayo RS, et al. Plasma ghrelin levels after diet-induced weight loss or gastric bypass surgery. $N$ Engl J Med. 2002;346(21):1623-1630.

114. Cummings DE, Clement K, Purnell JQ, et al. Elevated plasma ghrelin levels in Prader Willi syndrome. Nat Med. 2002;8(7):643-644.

115. Zigman JM, Elmquist JK. In search of an effective obesity treatment: a shot in the dark or a shot in the arm? Proc Natl Acad Sci U S A. 2006;103(35):12961-12962.

116. Farooqi IS, Matarese G, Lord GM, et al. Beneficial effects of leptin on obesity, T cell hyporesponsiveness, and neuroendocrine/metabolic dysfunction of human congenital leptin deficiency. J Clin Invest. 2002;110(8):1093-1103.

117. Heymsfield SB, Greenberg AS, Fujioka K, et al. Recombinant leptin for weight loss in obese and lean adults: a randomized, controlled, dose-escalation trial. JAMA. 1999;282(16):1568-1575.

118. Zelissen PM, Stenlof K, Lean ME, et al. Effect of three treatment schedules of recombinant methionyl human leptin on body weight in obese adults: a randomized, placebo-controlled trial. Diabetes Obes Metab. 2005;7(6):755-761.

119. Hukshorn CJ, Westerterp-Plantenga MS, Saris WH. Pegylated human recombinant leptin (PEG-OB) causes additional weight loss in severely energy-restricted, overweight men. Am J Clin Nutr. 2003;77(4):771-776.

120. Rosenbaum M, Goldsmith R, Bloomfield D, et al. Low-dose leptin reverses skeletal muscle, autonomic, and neuroendocrine adaptations to maintenance of reduced weight. J Clin Invest. 2005;115(12): 3579-3586.
121. Oral EA, Simha V, Ruiz E, et al. Leptin-replacement therapy for lipodystrophy. $N$ Engl J Med. 2002;346(8):570-578.

122. Batterham RL, Cowley MA, Small CJ, et al. Gut hormone PYY(3-36) physiologically inhibits food intake. Nature. 2002;418(6898): 650-654.

123. Batterham RL, Cohen MA, Ellis SM, et al. Inhibition of food intake in obese subjects by peptide YY3-36. N Engl J Med. 2003;349(10): 941-948.

124. Gantz I, Erondu N, Mallick M, et al. Efficacy and safety of intranasal peptide YY3-36 for weight reduction in obese adults. J Clin Endocrinol Metab. 2007;92(5):1754-1757.

125. Wynne K, Park AJ, Small CJ, et al. Subcutaneous oxyntomodulin reduces body weight in overweight and obese subjects: a double-blind, randomized, controlled trial. Diabetes. 2005;54(8):2390-2395.

126. Barsh GS, Farooqi IS, O'Rahilly S. Genetics of body-weight regulation. Nature. 2000;404(6778):644-651.

127. Huszar D, Lynch CA, Fairchild-Huntress V, et al. Targeted disruption of the melanocortin-4 receptor results in obesity in mice. Cell. 1997;88(1):131-141.

128. Butler AA, Marks DL, Fan W, Kuhn CM, Bartolome M, Cone RD. Melanocortin-4 receptor is required for acute homeostatic responses to increased dietary fat. Nat Neurosci. 2001;4(6):605-611.

129. Xiang Z, Pogozheva ID, Sorenson NB, et al. Peptide and small molecules rescue the functional activity and agonist potency of dysfunctional human melanocortin-4 receptor polymorphisms. Biochemistry. 2007;46(28):8273-8287.

130. Madison LD, Marks DL. Anticatabolic properties of melanocortin-4 receptor antagonists. Curr Opin Clin Nutr Metab Care. 2006;9(3): 196-200.

131. Cai M, Mayorov AV, Ying J, et al. Design of novel melanotropin agonists and antagonists with high potency and selectivity for human melanocortin receptors. Peptides. 2005;26(8):1481-1485.

132. Bray GA, Greenway FL. Pharmacological treatment of the overweight patient. Pharmacol Rev. 2007;59(2):151-184.

Diabetes, Metabolic Syndrome and Obesity: Targets and Therapy

\section{Publish your work in this journal}

Diabetes, Metabolic Syndrome and Obesity: Targets and Therapy is an international, peer-reviewed open-access journal committed to the rapid publication of the latest laboratory and clinical findings in the fields of diabetes, metabolic syndrome and obesity research. Original research, review, case reports, hypothesis formation, expert opinion and commentaries are all considered for publication. The manuscript management system is completely online and includes a very quick and fair peer-review system, which is all easy to use. Visit http://www.dovepress.com/testimonials.php to read real quotes from published authors. 